\title{
Woody Species Composition in Relation to Spatial and Environmental Gradients in Acacia-Commiphora Vegetation Ecosystem of Ethiopia
}

\author{
Debissa Lemessa*, Fisseha Asmelash, Yayehrad Teka, Sisay Alemu, Motuma Didita, Seid Melesse \\ Forest and Range Land Plant Biodiversity Directorate, Ethiopian Biodiversity Institute, Addis Ababa, Ethiopia
}

Email address:

lemdeb@yahoo.com (D. Lemessa)

${ }^{*}$ Corresponding author

\section{To cite this article:}

Debissa Lemessa, Fisseha Asmelash, Yayehrad Teka, Sisay Alemu, Motuma Didita, Seid Melesse. Woody Species Composition in Relation to Spatial and Environmental Gradients in Acacia-Commiphora Vegetation Ecosystem of Ethiopia. International Journal of Natural Resource Ecology and Management. Vol. 2, No. 3, 2017, pp. 53-59. doi: 10.11648/j.ijnrem.20170203.12

Received: March 16, 2017; Accepted: March 28, 2017; Published: April 13, 2017

\begin{abstract}
Woody species composition at local scale has been studied well in the tropics. However, how the species composition is related to the spatial and environmental gradients was poorly studied. Here, we examined the effects of the topographic aspects and altitude gradient on the species composition across four sites of Acacia-Commiphora woodland and bushland ecosystem. We collected data on the number of species, number of individuals, dbh and total height for those dbh was $\geq 2.5 \mathrm{~cm}$ from ten quadrates (size: $50 \times 50 \mathrm{~m}$ each) along transect of about $2 \mathrm{kms}$ laid out in each four sites. Altitude was taken with handheld GPS (Garmin GPSMAP 60CSx) and topographic aspects were recorded for each quadrate. The species composition was dissimilar among the four sites, across altitudinal gradients and topographic aspects. Here, the majority of the rare species are specific to each site, for example, Olea europea is the rare species in site (A) but not recorded in the rest of the three sites. Our overall results underscore the importance of considering the spatial scales and environmental variables in designing conservation methods. Nevertheless, identifying the biotic attributes driving the species composition in the ecosystem envisages further studies.
\end{abstract}

Keywords: Altitude, Aspect, Conservation, Ecosystem, Spatial Scales, Species Composition

\section{Introduction}

Understanding the factors driving the spatial patterns of species composition is critically important in conservation planning $[1,2]$. However, since vegetation is not spatially uniformly distributed, it is a challenge but also a major task in community ecology to understand such heterogeneity [3]. For example, some areas are comprised of high diversity, other extreme areas are devoid of vegetation while most lie in between teemed with intermediate diversity [4]. Therefore, understanding the patterns of species composition across spatial scales and environmental gradients is essential for developing conservation strategies mainly under the currently prevailing climate change $[5,6]$.

The change in species composition at different spatial scales naturally occurs when the local species diversity complements the regional species pool and in vice-versa when the regional species diversity supplements the local species diversity [7].
Moreover, due to the random occurrence of stochastic disturbances, fragmentation of natural habitats and other ecological processes conserving the ecosystem at regional scale does not guarantee the protection of rare species and merely conservation efforts at the specific species level may not lead to the healthy ecosystem at regional scale [7]. These natural and artificial dynamic processes are drivers of species composition across spatial scales and are fundamental in vegetation description $[3,6,8,9]$.

The knowledge of the species diversity across spatial scales is crucial to develop conservation strategies and ensure biodiversity conservation $[10,11]$. Despite there is high diversity of vegetation ecosystems in the tropical regions our understanding of the spatial pattern and extent of change in species composition is poor [12]. In other regions, the dissimilarity in species composition across spatial and environmental gradients was shown by previous studies [1, 6]). In tropical regions, most of the previous studies were 
limited to the local scales or case studies and less is understood across scales [13]. For example, in Ethiopia, many of the earlier studies described vegetation structure only at local scale [14-19]. Nevertheless, environmental variables such as, altitude and aspect could be important driver of vegetation composition [20]. Here, we aim to fill this gap by performing woody species composition analysis across four sites in Acacia-Commiphora woodland and bushland ecosystem of Ethiopia (Figure 1).

The Acacia-Commiphora woodland and bushland ecosystem is located relatively in dry low land areas and lies between altitudes $900-1900 \mathrm{~m}$ a.s.l. and is one of the most diverse ecosystems identified in Ethiopia [21]. Hence, we hypothesized that the woody species composition is dissimilar across spatial and environmental gradients. The assumption behind this is that the differences in species specific properties, the variation in habitat suitability and other ecological processes may cause the changes in species composition across sites and environmental gradients such as, altitude and topographic aspects.

\section{Materials and Methods}

\subsection{Study Sites}

The study was performed in Liben woreda of Guji zone of Oromia region, south Ethiopia (Figure 1, $5^{\circ} 35^{\prime}-5^{\circ} 41^{\prime} \mathrm{N}$ and $39^{\circ} 29^{\prime}-39^{\circ} 34^{\prime}$ E, Figure 1). The topography of the study area is characterized by moderate, undulating land, flat slopes and lies at $1175-1591 \mathrm{~m}$ a.s.l. The vegetation type belongs to Acacia-Commiphora woodland and bushland ecosystem which is largely found in dry low land area in the rift valley region. This ecosystem is mainly dominated by drought tolerant Acacia and Commiphora tree species. The soil on the sloppy side of the topography is sandy, reddish brown in colour but at the lower altitudes with flat areas the soil is black, alluvial and vertisols where the drainage is impeded. The area gets mean annual rainfall of between $200-600 \mathrm{~mm}$ with bimodal seasons where the main rainfall season is during April-May and the minor one is in October-November [21].

\subsection{Study Design}

Before we started the actual field data collection, we performed reconnaissance survey to get the overview of the study area during May 05-08, 2015. On top of this, we used satellite image in Google Earth to randomly select four sites (identified as site A, B, C and D) in north-south direction (Figure 1) having similar structure. In general, a vegetation study was conducted on a total area of $40.7 \mathrm{~km}^{2}$. The minimum and maximum distance among sites was 1.27-2.7 $\mathrm{km}$. On each of the four sites selected, one straight line transect (approx. 2kms) that longitudinally cross through the vegetation was laid out so as to capture the environmental gradients by walking using hand-held compass (Figure 1). Ten quadrates (size: $50 \times 50 \mathrm{~m}$ each) were laid out along each transect with about $200 \mathrm{~m}$ interval among the quadrates. Following this method, data was collected from four sites during 09-18 May, 2015. Moreover, specimens of trees and shrubs were collected and identified to different taxonomic levels (genera and species) at the herbarium of Ethiopian biodiversity institute and Addis Ababa University.

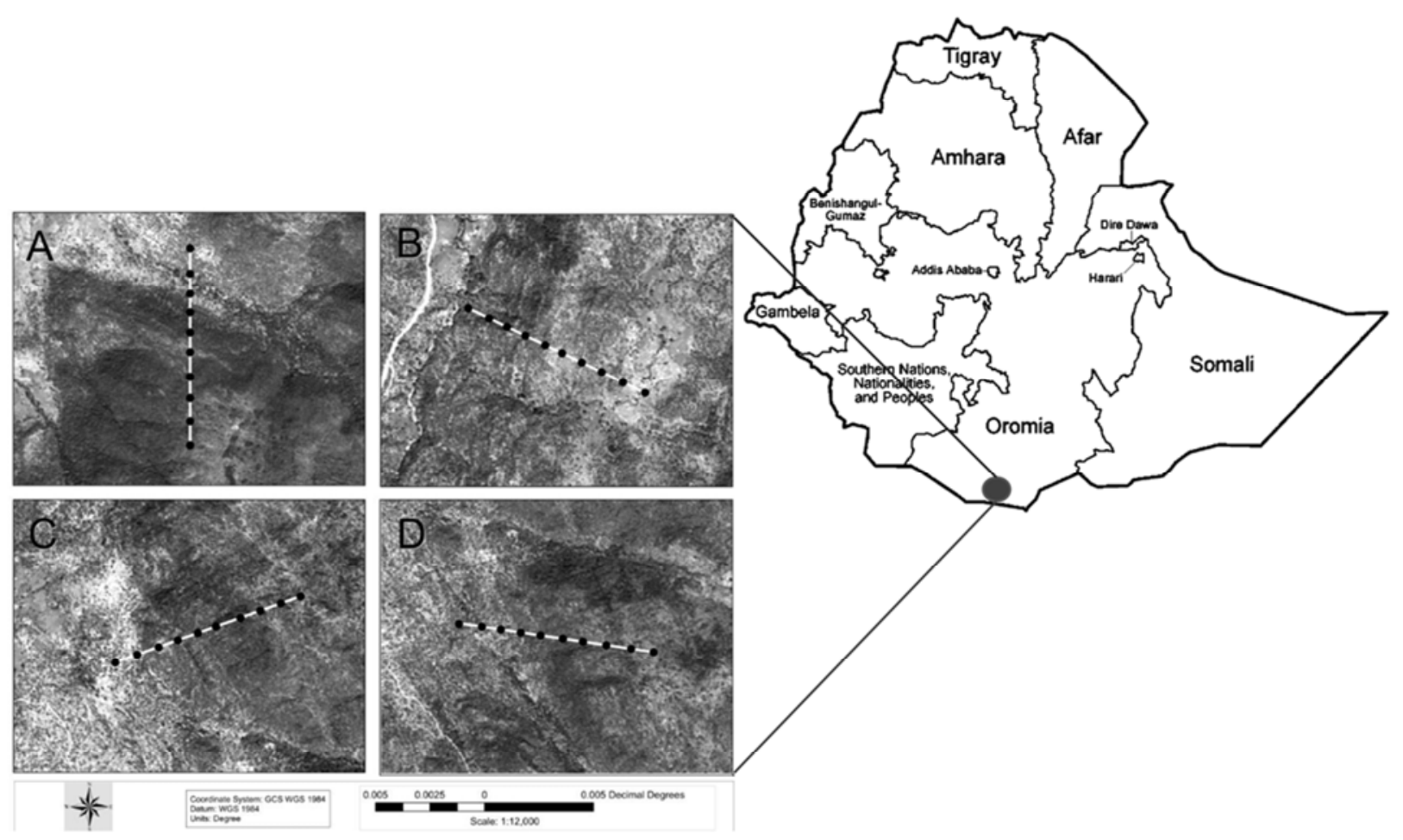

Figure 1. The vegetation assessment sites shown in relation to the relative location in Oromia region Ethiopia. The lines indicated with dots are transects (approx. each $2 \mathrm{kms}$ long) and the dots are the sample plots. 


\subsection{Data Collection}

The vegetation data including the number of woody plant species, number of individuals of each species, dbh and total height were recorded for both trees and shrubs whose dbh was $\geq 2.5 \mathrm{~cm}$. Along with this vegetation data, we also recorded other environmental variables such as altitude, topographic aspects of the quadrates, and geographic points were taken with handheld GPS (Garmin GPSMAP 60CSx) for each quadrate along each transect. The variation between the lowest and the highest altitudes of the study area was 416m (1175-1591 m a.s.1.).

\subsection{Statistical Analysis}

The effect of altitude and aspect on the woody species richness was tested using the generalized linear mixed effects model with Poisson distribution using glmer function in lmer4 package [22]. In the model, altitude and aspect variables were included in the model as fixed factors while sites identity were considered as random factors. Here, altitude was standardized before it was included in the model. The multivariate methods such as PCA ordination and Adonis function with permutation 999 (in vegan package) were used to analyze the dissimilarity in species composition among sites and the effect of the environmental variables on species composition. The Adonis function is analogous to multivariate analysis of variance and uses the dissimilarity distance matrices [23]. For all the above analysis, R statistical program (version 3.2.3) was used [24]. To identify the most common and rare species, the importance value of each species ( $\mathrm{Ij}$ ) was calculated according to the following equation $[25,26]$.

$$
I_{j}=100\left(n_{j} / N\right)+\left(d_{j} / D\right)+\left(x_{j} / X\right)
$$

where $I_{j}$ is the importance value of the $j$ th species, $n_{j}$ is the number of quadrates where the $\mathrm{jth}$ species is present, $\mathrm{N}$ is the total number of sampling units, $d_{j}$ is the number of individuals of the jth species present in sample population, $\mathrm{D}$ is the total number of individuals in sample population $\left(D \_\sum d j\right), x_{j}$ is the sum of size parameter (generally basal area or volume) for the $\mathrm{jth}$ species, and $\mathrm{X}$ is the total size parameter across all species $X_{-} \sum \mathrm{x}_{\mathrm{j}}$. To illustrate the species sampling efforts across the four sites (A-D), species accumulation curve was computed with samplebased incidence within EstimateS program, Version 9.1.0 [27].

\section{Results}

\subsection{Species Richness}

Altogether 66 woody species of shrubs and trees that belong to 26 families were recorded from the four sites (site A-D) inventoried in Acacia-Commiphora woodland and bushland ecosystem. Forty six woody species $(70 \%)$ from site (A), 38 (57.6\%) from site (B), 31 (47\%) from site (C) and 37 (56\%) were recorded from site (D). From the total of 66 species 11 species $(16.7 \%)$ were common to the four sites, 6 species $(9 \%), 5$ species $(7.6 \%), 7$ species $(10.6 \%)$ and 2 species (3\%) respectively were exclusive to each site (Figure 2). The mean number of species from the four sites is 38 species of shrubs and tree species. The species sampling efforts across the four sites (A-D) was shown in Figure 3. The estimated accumulative number of species from ten sample plots of each site with $95 \%$ confidence interval does not show a significant variation in sampling efforts among the four sites (Figure 3). The generalized mixed effects model showed that the species richness was significantly differed by aspect $\left(\chi_{(1,7)}^{2}=17.16, P=0.012\right.$, Figure 4).

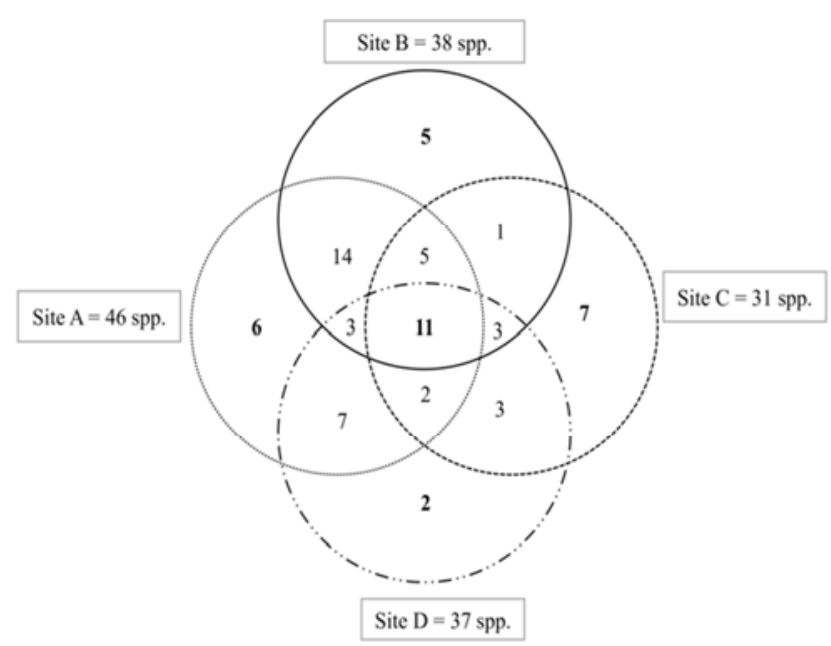

Figure 2. The vain diagram showing the pattern of species composition among four sites (A-D) in Acacia-Commiphora woodland and bushland ecosystem. The numbers in the vain diagram indicate the number of species which are common across sites and also exclusive to each site.

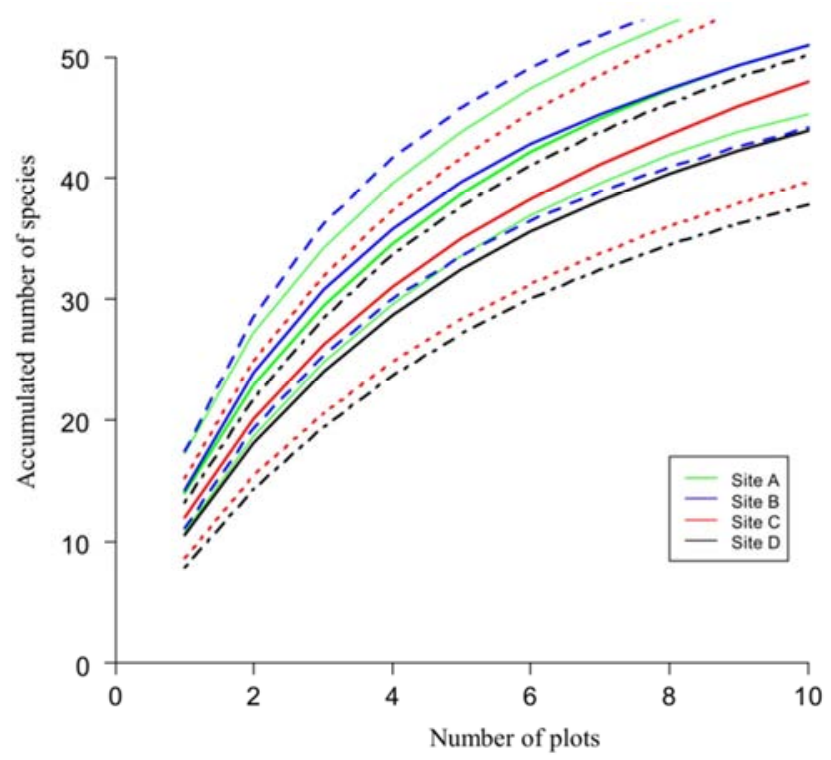

Figure 3. Species accumulation curve showing the accumulated number of species across plots with 95\% confidence interval for the four sites (A-D). 


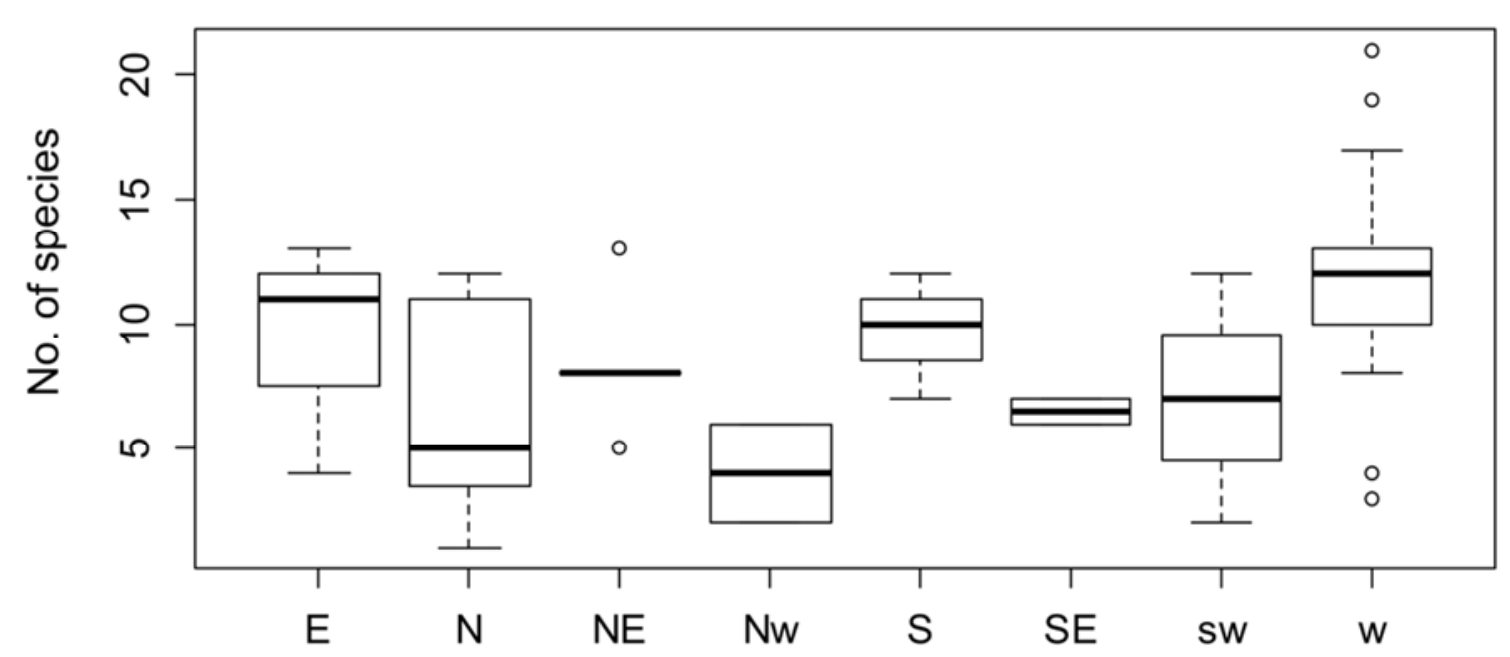

Figure 4. Boxplot showing the number of species in relation to the topographic features, east (E), northeast (NE), northwest (NW), south(S), southeast (SE), southwest (SW) and west (W) aspects.

\subsection{Species Composition}

The Adonis analysis denoted that the woody species composition was dissimilar among the four sites $\left(\mathrm{F}_{(3,39)}=\right.$ $4.28, P=0.001)$. The PCA showed that the environmental factors such as altitude and aspects explained the variation among quadrates (Figure 5) indicating the importance of modelling the species composition in relation to the environmental gradients or PCA axes. Here, PC 1 and PC 2 accounted for $50.6 \%$ and $14 \%$ respectively, of the variation among the quadrates and sites. The aspects such as $\mathrm{W}, \mathrm{SW}$, $\mathrm{NW}, \mathrm{E}, \mathrm{S}$ and altitude explained the variation in the first axis (PC1) while aspects including N, W and NW explained the variation in the second axis (PC2).

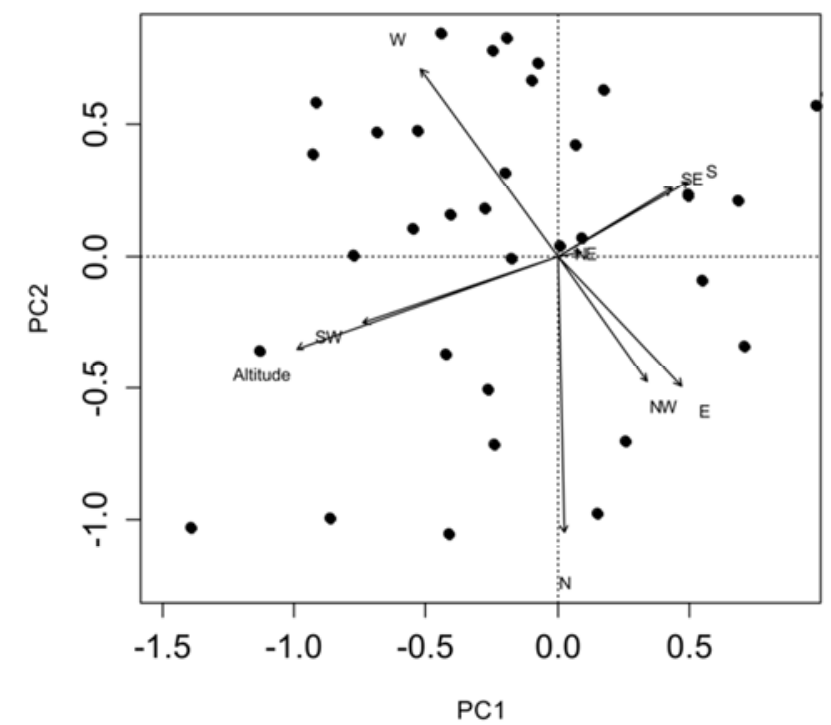

Figure 5. PCA plot showing the first and second principal components and the relative position of the quadrates (black points) in ordination space. The arrows indicate how the topographic features such as altitude and aspects are associated with the sample quadrates and the corresponding species composition across sites.

The result of the important value index analysis (IVI, hereafter), showing common and rare species across sites was shown in Figure 6. Even if there is no standard for cutoff values of IVI to decide which species are common and rare, the five top common tree species in site (A) are Acacia sp2, Psydrax schimperiana, Commiphora sp and Terminalia browni with higher IVI (range: 9.2-31.5, Figure 6A), Acacia sp2, Commiphora gileadensis, Terminalia browni and Stericulia Africana in site (B) (IVI range: 5.7-8.9, Figure 6B), Grewia bicolor, Acacia sp2, Lannea triphylla, Acacia tortlis and Commiphora sohaerocarpa in site (C) (IVI range: 5-32, Figure 6C) and Acacia sp2, Comiphora ogadensis, Haplocoelum foliolosum, kirkia burger and Terminalia browni in site (D) (IVI range: 8.9-102, Figure 6D). Among these, Acacia sp2 is one of the commonly found tree species across all sites (Figure 6). On the other extreme, the most five rare species had lower IVI of range between 0.2-0.7 (Figure 6A-D).

\section{Discussions}

The woody species composition in in AcaciaCommiphora woodland and bushland ecosystem was dissimilar among the sites. Five to thirteen percent of the recorded species were exclusive to each site (Figure 2). The dissimilarity in species composition was also depicted by altitude gradient and topographic aspects (i.e. the direction to where the slope if facing). This variation could be due to the different habitat conditions formed by different topographic features, for example, in moisture availability; this is most likely since our study ecosystem lies in a low land area where rainfall is erratic and soil is fragile that may impact the plant diversity and the corresponding species composition. In line with this result, the study conducted at two sites in Nepal found significant variation in woody species composition between northeast and southwest facing slopes [28]. This pattern may also indicate the indirect impact of altitudinal gradients and topographic aspects on the species composition by limiting the habitat 
quality and suitability such as soil fertility, precipitation and temperature to support the vegetation which thereby shape the spatial structure of the community assemblages [29-33, 11]. Moreover, our study is in congruent with the findings of the previous studies [33-36] that indicated the effect of altitude gradient on species composition. Here, the species composition may be determined by the ecological processes such as environmental filters, biotic interactions and species specific neutral mechanism properties such as dispersal limitation [20, 30, 37, 38]. Specifically, the variation in edaphic and microclimatic factors across spatial scales, altitude gradient and the topographic aspects differently affect the species adaptability and thereby the composition structure and distribution as this was also found by the previous findings from China and South Africa [11, 12, 35]. In line with this, our results pointed out that the majority of the rare species are specific to each site that may attribute towards the heterogeneities in species composition among these sites. For example, Olea europea is the rare species in sites (A) but it is not even recoded in sites (B-D, Figure 6). In this case, it is only Acacia $\mathrm{sp} 2$ tree species which was found to be the common one across these four sites (A-D, Figure 6). These results emphasize that the conservation system that targets each specific species is vital since conserving only the ecosystem at large scale may not be adequate to support the conservation of the rare/threatened species in the system [7, 39]. This notion could also work for other mobile organisms such as, bird and insect pollinator communities in which the conservation of ecosystem as a system would also consider the rare/threatened species [40, 41]. In general, our study indicates the importance of exploring the species composition in relation to the spatial and environmental gradients to identify the appropriate conservation approach and correspondingly set conservation priority that fits to each site and species characteristics in Acacia-Commiphora woodland ecosystem.
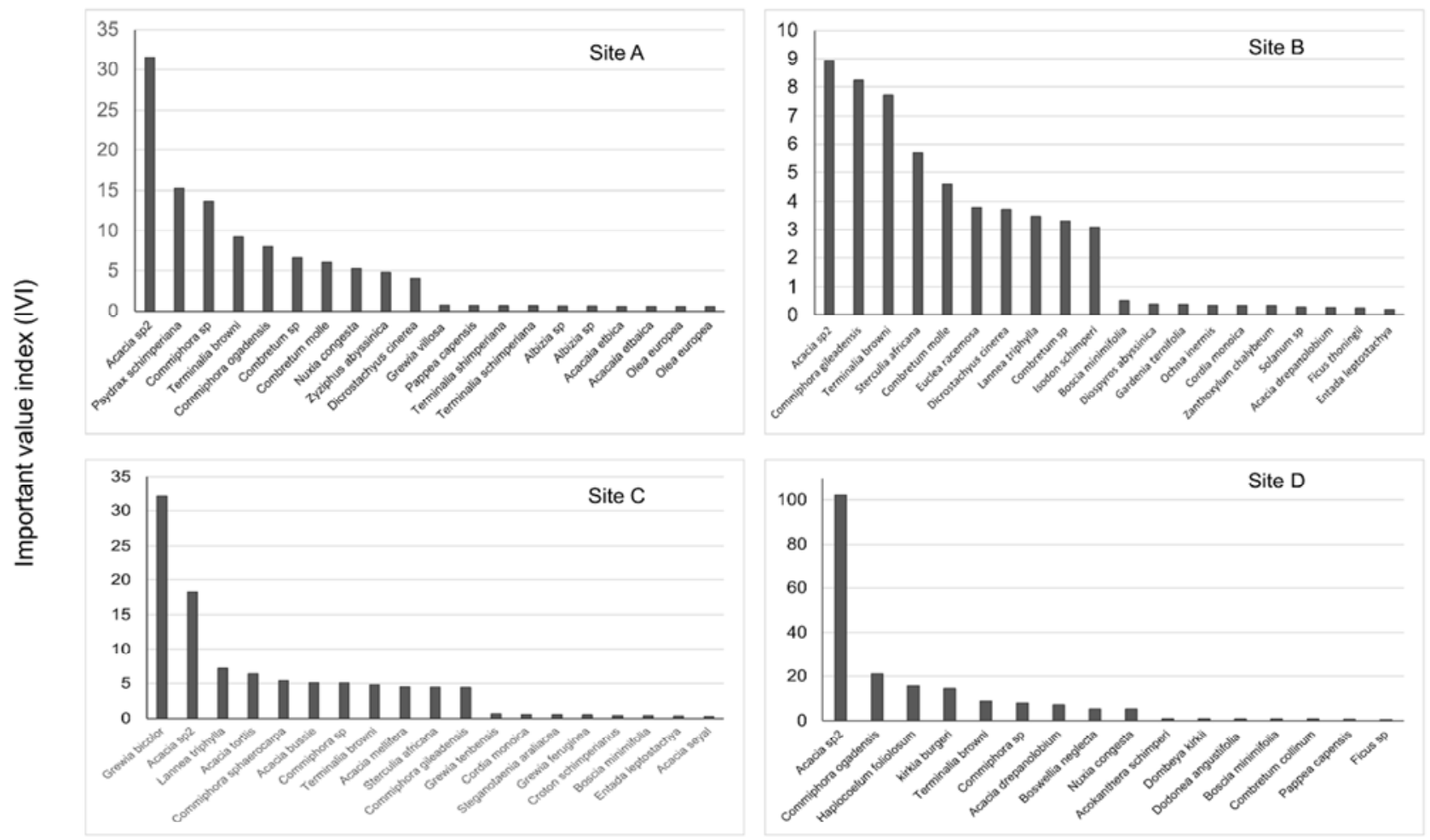

Woody plant species

Figure 6. The most abundant (IVI $\geq 3.1)$ and rare (IVI $\leq 0.66)$ woody plant species were shown across the four study sites $(A-D)$.

\section{Conclusion}

The present study underscores that the woody species composition exhibits dissimilarity among the sites, altitudinal gradient and topographic aspects in Acacia-Commiphora woodland ecosystem. The majority of the rare species are specific to each site, for example, Olea europea is the rare species specific to site (A) but was not recorded in the rest of the study sites. These results demonstrates that the composition of woody species can better be understood if the vegetation analysis is performed beyond the local scale. Overall, our results accentuate the vitality of the conservation approach that considers both the whole system at large scale and the specific species since conserving solely the whole system may not necessarily mean mean that the rare and threatened species are conserved. Nevertheless, identifying the biotic processes determining the woody species composition among sites in the ecosystem envisages further studies. 


\section{References}

[1] Kouba, Y., Martínez-García, F., De Frutos, Á. \& Alados, C. L. (2014) Plant $\beta$-diversity in human-altered forest ecosystems: the importance of the structural, spatial, and topographical characteristics of stands in patterning plant species assemblages. Eur. J. For. Res. 133, 1057-1072.

[2] Mereta, S. T., Boets, P. \& Bayih, A. A. et al. (2012) Analysis of environmental factors determining the abundance and diversity of macro invertebrate taxa in natural wetlands of Southwest Ethiopia. Ecol. Inform. 7, 52-61.

[3] Hylander, K. (2006) Riparian zones increase regional species richness by harboring different, not more, species : comment. Ecol. 87, 2126-2128.

[4] Gaston, K. J. (2000) Global patterns in biodiversity. Nature 405, 220-227.

[5] Hylander, K., Nilsson, C., Jonsson, B. G. \& Göthner, T. (2005) Differences in habitat quality explain nestedness in a land snail meta-community. Oikos 108, 351-361.

[6] Baselga, A. (2010) Partitioning the turnover and nestedness components of beta diversity. Glob. Ecol. Biogeogr. 19, 134 143.

[7] Tscharntke, T., Tylianakis, J. M. \& Rand, T. A. et al. (2012) Landscape moderation of biodiversity patterns and processes eight hypotheses. Biol. Rev. 87, 661-685.

[8] Leibold, M. A. \& Mikkelson, G. M. (2002) Coherence, species turnover, and boundary clumping : elements of metacommunity structure. Oikos 97, 237-250.

[9] Baselga, A. (2012) The relationship between species replacement, dissimilarity derived from nestedness, and nestedness. Glob. Ecol. Biogeogr. 21, 1223-1232.

[10] Saraiva, D. D., Da Silva De Sousa, K. \& Overbeck, G. E. (2015) Multiscale partitioning of cactus species diversity in the South Brazilian grasslands: Implications for conservation. J. Nature. Conserv. 24, 117-122.

[11] Zhang, Q., Hou, X. \& Li, F. Y. et al. (2014) Alpha, beta and gamma diversity differ in response to precipitation in the Inner Mongolia Grassland. PLoS ONE 9, e93518.

[12] Scholtz, R. S., Iker, G. A.K. \&, Mit, I. P. J. S. (2014) Identifying drivers that influence the spatial distribution of woody vegetation in Kruger National Park, South Africa. Ecosphere 5, 71 http://dx.doi.org/10.1890/ ES14-00034.1.

[13] Socolar, J. B., Gilroy, J. J., Kunin, W. E. \& Edwards, D. P. (2015) How should beta-diversity inform biodiversity conservation? Trends. Ecol. Evol. 31, 67-80.

[14] Soromessa, T., Teketay, D. \& Demissew, S. (2004) Ecological study of the vegetation in Gamo Gofa Zone, southern Ethiopia. Trop. Ecol. 45, 209-221.

[15] Senbeta, F. \& Teketay, D. (2002) Soil seed bank in plantations and adjacent natural dry Afromontane rainforests of central and southern Ethiopia. Trop. Ecol. 43, 229-242.

[16] Yineger, H., Kelbessa, E., Bekele, T. \& Lulekal, E. (2008) Floristic composition and structure of the dry afromontane forest at bale mountains national park, Ethiopia. SINET: Ethiop. J. Sci. 31, 103-120.
[17] Didita, M., Nemomissa, S. \& Woldemariam, T. (2010) Floristic and structural analysis of the woodland vegetation around. J. For. Res. 21, 395-408.

[18] Zegeye, H., Teketay, D. \& Kelbessa, E. (2011) Diversity and regeneration status of woody species in Tara Gedam and Abebaye forests, northwestern Ethiopia. J. For. Res. 22, 315328.

[19] Dalle, G. (2015) Floristic composition, population structure and conservation status of woody species in Shashemene-Munessa natural forest, Ethiopia. Ethiop. J. Biodiv. 1, 21-44.

[20] Brown, J. H. \& Lomolino, M. V. (1998) Biogeography (2 ${ }^{\text {nd }}$ edn). Courier Companies, Sunderland.

[21] Friis, I., Demissew, S. \& Van Breugel, P. (2010) Atlas of the Potential Trees/shrubs of Ethiopia. Det Kongelige Danske Videnskabernes Selska, Specialtrykkeriet Viborg a-s, Copenhagen, Denmark.

[22] Bates, D., Maechler, M., Bolker, B. \& Walker, S. (2015) lme4: Linear mixed-effects models using Eigen and S4.

[23] Oksanen, J. (2015) Multivariate analysis of ecological communities in $\mathrm{R}$ : vegan tutorial. Community Ecology Package. http://vegan.r-forge.r-project.org/.

[24] R Core Team. (2015) R: A language and environment for statistical computing. $R$ Foundation for Statistical Computing, Vienna, Austria. URL http://www.Rproject.org/.

[25] Grieg-Smith, P. (1957) Quantitative plant ecology. Academic Press, New York.

[26] Husch, B., Beers, T. W. \& Kershaw, J. A. (2003) Forest mensuration. Wiley, New York.

[27] Colwell, R. K. (2013) EstimateS, Version 9.1: Statistical Estimation of Species Richness and Shared Species from Samples (Software and User's Guide). Freeware for Windows and Mac OS.

[28] Paudel, S. \& Vetaas, O. R. (2014) Effects of topography and land use on woody plant species composition and beta diversity in an arid Trans-Himalayan landscape, Nep. J. Mount. Sci. 11, 1112-1122.

[29] Austin, M. P. (1980) Searching for a model for use in vegetation analysis. Vegetatio. $42,11-21$.

[30] Legendre, P., Mi, X., Ren, H., Ma, K., Yu, M., Sun, I. F. \& He, F. (2009) Partitioning beta diversity in a subtropical broadleaved forest of China. Ecol. 90, 663-674.

[31] Sandetrs, N. J. \& Rahbek, S. (2012) The patterns and causes of elevational diversity gradients. Ecography. 35, 1-3.

[32] Moeslund, J. E., Arge, L. \& Bøcher, P. K. et al. (2013) Topography as a driver of local terrestrial vascular plant diversity patterns. Nord. J. Bot. 31, 129-144.

[33] Qiao, X., Li, Q., Jiang, Q. \& Lu, J. et al. (2015) Beta diversity determinants in Badagongshan, a subtropical forest in central China. Sci. Repor. 5, 17043.

[34] Tang, Z., Fang, J. \& Chi, X. et al. (2012) Patterns of plant beta-diversity along elevational and latitudinal gradients in mountain forests of China. Ecography 35, 001-009. 
[35] Huo, H., Feng, Q. \& Su, Y. (2015) Shrub communities and environmental variables responsible for species distribution patterns in an alpine zone of the Qilian Mountains, northwest China. J. Mount. Sci. 12, 166-176.

[36] Lee C-B \& Chun, J-H. (2016) Environmental drivers of patterns of plant diversity along a wide environmental gradient in Korean temperate forests. Forests 7:1-16.

[37] Chust, G., Chave J, Condit, R., Aguilar, S., Lao, S. \& Pérez, R. (2006) Determinants and spatial modeling of tree betadiversity in a tropical forest landscape in Panama. J. Veg. Sci. $17,83-92$.

[38] De Cáceres, M., Legendre, P., Valencia, R. \& Cao M. et al. (2012) The variation of tree beta diversity across a global network of forest plots. Glob. Ecol. Biogeogr. 21, 1191-1202.
[39] Jost, L., Devries, P., Walla, T., Greeney, H., Chao, A. \& Ricotta, C. (2010) Partitioning diversity for conservation analyses. Divers. Distrib. 16, 65-76.

[40] Aerts, R., Spranghers, S., Şekercioğlu, ÇH. (2016)

Conservation of ecosystem services does not secure the conservation of birds in a Peruvian shade coffee landscape. Bird Conserv. Intern. 1-12. http://doi.org/10.1017/S0959270916000149

[41] Klejin D, Winfree R, Bartomeus, I. et al. (2015) Delivery of crop pollination services is an insufficient argument for wild pollinator conservation. Nature Commun. 6: 7414. Doi: $10.1038 /$ ncomms 8414 . 